\title{
Innovation process of machine harvesting of laid peas and its efficiency
}

\author{
Vladimir Karpenko ${ }^{1}$, Ivan Masienko ${ }^{1, *}$, and Lyudmila Eranova ${ }^{1}$ \\ ${ }^{1}$ FSBEI HE «Kuban State Agrarian University named after I.T.Trubilin», 350044, Krasnodar, Russia
}

\begin{abstract}
In this work there was made the analysis of the valuable properties of peas and the problem of harvesting without losses, based on the description of the new way of harvesting the laid peas by direct combine harvesting, including the separation of stems from the soil and their transportation to threshing. The method differs in that the separation of the stems from the soil making by separation, and before separation, they are cut off in a vertical plane located on the side of the harvesting machine of the main array. There was offered a device for harvesting, as well as the results of the introduction of the method and device into production, which will increase the harvest in 1.7 times and will lead to a saving of diesel fuel by $34 \%$.
\end{abstract}

Peas are a valuable food and fodder crop. Mature pea seeds contain $22 . .34 \%$ protein, $20 . .48 \%$ starch, $4 . . .10 \%$ sugar and about $1 \%$ fat. Per 1 feed unit of peas there are more than $150 \mathrm{~g}$ of digestible protein, while corn, barley, oats - only 59, 70 and $81 \mathrm{~g}$ (with zootechnical rate $110 . .120 \mathrm{~g}$ ). One ton of pea protein is cheaper than the corresponding amount in feed units, for example, in yeast -5 times, in fish flour - 6 times, in grain of field forage crops -3 times. Each ton of pea seeds introduced into the diet of animals can save about 2.5 tons of concentrates $[1,2]$.

A minimum amount of fertilizers is required for the cultivation of peas. In addition, $40 \ldots 80 \mathrm{~kg} / \mathrm{ha}$ of nitrogen remains in the soil after its harvesting, a number of elements necessary for plant nutrition is accumulated in a more accessible form, soil physical properties are improved, and therefore its fertility is increased.

Peas are one of the best predecessors for main food crops, including winter wheat, providing an increase in grain yield by $0.8 \ldots 1.1 \mathrm{t} / \mathrm{g}$. It is used in both main and intermediate crops to obtain additional harvest. Thus, the advantage of peas is the universality of use for food and feed purposes, the richness of essential amino acids, increase of soil fertility, simplicity and accessibility of cultivation technology, adaptability to different agrolandscape conditions of production, economy of material labor and energy resources and improving the agro-ecological situation.

In world agriculture, leguminous crops, which include peas, occupy about $11 \%$ of the total area of grain and leguminous crops.

Pea is one of main leguminous crops in the Russian Federation. Here the border of its distribution coincides with the border of agriculture since it is relatively low-demand for

\footnotetext{
${ }^{*}$ Corresponding author: ivan.masienko@yandex.ru
} 
heat (pea seeds can be produced at temperature of $1 \ldots 2^{0} \mathrm{C}$ ). The greatest distribution of this cultivar is in the Central Chernozem, Volga and North Caucasus regions, as well as in Western and Eastern Siberia. Peas have a high yield potential and, under favorable conditions, advanced agricultural enterprises of various regions of the country receive 3.5...4.0 $\mathrm{t} / \mathrm{ha}$ of seeds [3].

Peas occupy about $2 \%$ of the crop rotation in Krasnodar Territory. Here, its harvest is not stable over the years and is $20 \ldots 50 \%$ of its potential productivity. It restrains the expansion of the acreage of this valuable food and fodder crop, despite the fact that there were created the good conditions for Krasnodar Territory for the last decades, and principally new cultivated varieties of peas with high yield potential, which are more adequate to agrarian landscapes are grown.

Our researches of production machine technological processes of cultivation and harvesting of peas showed that late crops, the extended period of ripening and the tendency of beans to crack, and the stem of many varieties of peas to lodging lead to large quantitative and qualitative losses of seeds significantly exceeding the agrotechnical requirements for harvesting leguminous crops. Especially great quantitative and qualitative losses of pea seeds occur during the delay in harvesting, precipitation, stem lodging and weeds germination.

So when harvesting peas in extreme conditions (lodging and high debris) in the farms of the North Caucasus region, the loss of pea seeds reaches $50 \%$ of the crop, and in some years and more. [1]. It is caused by the fact that when harvesting laid peas by frontal widecut reapers, even at low shear, the stalks of beans are below the cutting unit and remain uncut. In addition, the stalks of peas intertwine into a single mass throughout the field and it is almost impossible to divide them with rod or torpedo dividers. During the operation the harvester along with cut pea plants by the working bodies of the reaper pull the uncut lateral stems. When moving the cut stems, the seeds are threshed and even the beans are separated from the stems, which fall to the surface of the soil and remain there.

It should also be noted that during the movement of the harvester the uncut lateral stalks of peas raised by dividers, wound on the drive sprockets and chain drive working bodies. It leads to a stop of the unit for cleaning the working bodies of the plant mass. The liberation of the rotating parts of the reaper from wounded stalks requires additional time and decrease the performance of the harvester, and sometimes it makes the work of reapers is impossible.

The harvesters operate in low gears during the threshing of laid peas, and it also reduces their productivity and increases fuel consumption.

Harvesting by traditional harvesters and pickers due to low productivity and large crop losses hinders the expansion of areas for the cultivation of peas.

As a result of the study of production processes of harvesting peas, we found that the main causes of large losses in extreme conditions (lodging and debris) is the lack of new methods of harvesting, special machines and working bodies, as well as the use of technology of cultivation of harvesting regardless to soil and climatic conditions not taking into account the frequent manifestation of extreme weather conditions, increasing soil degradation and socio-economic changes $[4,5]$.

Therefore, at present, an urgent problem for grain-producing agricultural enterprises is to increase the gross yield of pea seeds not by expanding the acreage, but by reducing the quantitative and qualitative losses of peas, which will make this cultivar more profitable and competitive. To solve this problem, an important task is the development and implementation of adaptive resource-efficient, environmentally friendly, technological and technical solutions and machine technologies in general, taking into account the biological characteristics of plants, methods of optimization of technological adjustments of working 
bodies of machines, methods and means of quality control of production of mechanized works of production organization, allowing to increase the pea yield significantly.

Our studies have revealed one of the biological features of pea plants, which consists in the fact that at the time of full ripeness of seeds, stalks and root system of plants are connected with each other extremely softened (macerated) root cervix, and throughout the plant cenosis - strong spiral curled tendrils. It allows separating plants from soil without efforts and without obligatory cutting with cutting units. At the same time, the roots of plants remain in the soil, and the stalks easily break away from it and carry away other stalks, still unbroken. In order not to pull the biomass from a large area, it is enough to divide the cenosis into strips of a certain width and remove them in turn [6].

We found that the work on the separation (tear off) from soil biomass of laid peas with macerated (softened) root cervix depends on the moisture content and yields of biomass and crop infestation and is $0.3 \ldots 0.5 \mathrm{~N} . \mathrm{cm} / \mathrm{cm}^{2}$, while the work made by harvester blades with a crank connecting rod mechanism is in the range of $1 \ldots .2 \mathrm{~N} . \mathrm{cm} / \mathrm{cm}^{2}$, i.e. several times less.

With regard to agrobiological characteristics of matured crops of laid pea, we have developed a new process and a technical solution - "method of harvesting peas by direct combine harvesting and a device for its implementation" [7].

Method of harvesting peas by direct combining, including the separation of stalks from the soil and their transportation to the threshing, is characterized by the separation of stalks from the soil occurs by the tearing off, and before tearing off it is occurred their cut-set in a vertical plane located at the lateral side of the harvesting machine of the main unit. The separation of the stalks is made by a pickup attachment, and the cutting of the stalks from the main unit is made at a width of not less than the width of the harvesting machine. The device for harvesting peas by direct harvesting, comprising a harvester with an inclined chamber, a threshing device and a working body attached to the inclined chamber for separating the stalks from the soil, characterized in that the working body for separating the stalks from the soil is in the form of a pickup attachment, equipped with vertical disk knives installed on both sides, taken forward in the direction of the harvester. Knives are equipped with flanges.

To implement this method on the Don - 1500 combine harvester, we hung a basic platform with the pickup attachment and spring fingers-rakes which was equipped with right and left vertical disk knives. The system of installation of vertical disk knives allows you to cut the dead and tangled pea plants from the main unit of the field on the width of the gripper - pickup attachment, and then tear them off with fingers-rakes and give to the threshing machine of the harvester by the conveyor. The disk knives installed in front of the pickup attachment can be adjusted vertically.

The basic technological scheme of the installation of vertical disk knives is shown in Figure 1. Right and left disk knives include a cutting wheel with the axle and the flange, the self-installing ball with the spine, adjusting sleeves and the bracket. The disk knife is fastened to a platform-pickup attachment of the harvester by two bolts. The support wheels of the platform-pickup attachment are removed before installing the disk knives with the ball.

A necessary slit between the ends of fingers of the pickup attachment and soil surface is established by means of adjusting sleeves before arrival of the harvester to the field. During cutting off the stalks with knives, mixed with the stems of the main array, flanges limit the penetration of the knives into the soil and at the same time press the stems to it, preventing them from being pressed into the soil with a knife. As the knives are brought forward in the course of movement of the harvester relative to the pickup attachment, only the strip of biomass is removed, cut off from the main array in the width of the platform-pickup attachment and the remained peas is not damaged by the wheels of the harvester. 

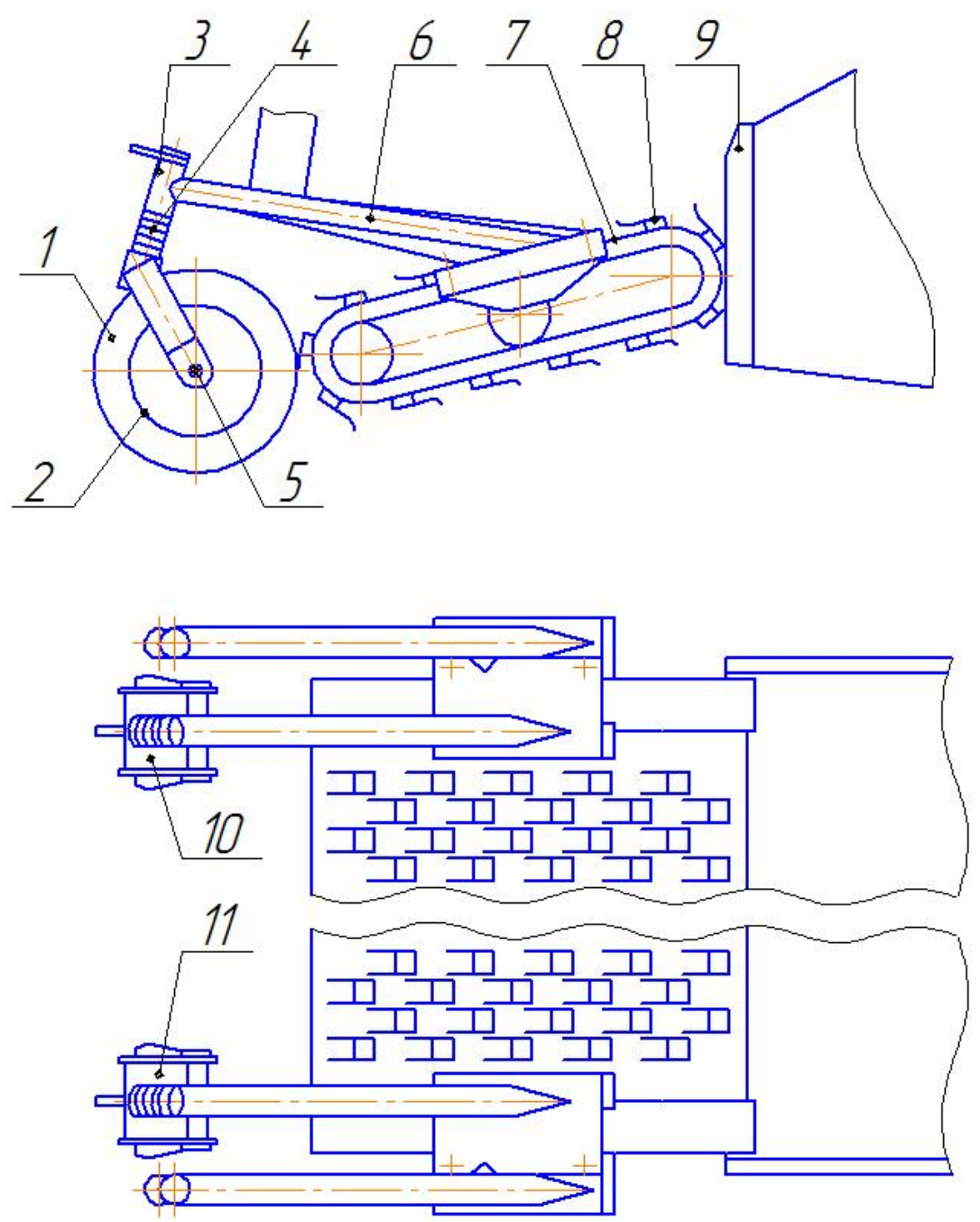

Fig. 1. Scheme of re-equipment of platform-pickup attachment of the harvester "Don-1500" for direct harvesting of laid peas.b1 - cutting disk; 2 - flange; 3 - self-installing ball; 4 - adjusted sleeves; 5 axis; $\sigma$ - blacket; 7 - conveyor belt of platform-pickup attachment; 8 - fingers - rakes of belt conveyor; 9 - platform-pickup attachment; 10,11 - right and left disk knives.

When moving the conveyor belt, its lower branch moves in the direction coinciding with the direction of movement of the harvester. The fingers are perpendicular to the belt. Fingers taking a position from horizontal to vertical carry out the rise of biomass in its lower part, grasping and separation from the soil with the following laying on the conveyor belt when bending around the guide roller belt. At the same time, the lower branch of the conveyor becomes the upper branch and, moving in the direction opposite to the direction of movement of the harvester, transports the pea biomass separated from the soil to the auger. Since harvesting is carried out in the phase of full ripeness of peas, the stalks in this period have the lowest humidity and the greatest fragility on the soil surface, and therefore they are easily detached from the soil with the fingers of the picker. In this regard the separation of stalks from the soil requires minimum efforts, the loss of grain and pea beans during harvesting is reduced. It should also be noted that the separation of the stalks from the soil by the fingers of the picker is made in the vertical plane, thereby also reducing the 
loss of seeds, while the separation of the stalks from the soil by the cutting machine of the reaper on the stems are affected by cross-horizontal forces that cause fluctuations in the stalks, their separation from the beans, as well as the exfoliation of seeds, which leads to crop losses.

The design and installation of additional working bodies on the platform- pickup attachment provided free grasp and exit from the biomass of peas, its taking off the soil surface and its supply to the threshing machine of the harvester. At the same time, gaps (missing stalks in the phase of their grasp and separation from the soil surface) were excluded and there were no excessive repeated runs of fingers - rakes. In addition, a continuous uniform supply of biomass to the subsequent working bodies was carried out, as well as the free exit of the fingers-rakes from the mass without dragging it under the conveyor belt.

To do this, it is important to choose and set the kinematic mode of operation of the harvesting unit $\lambda$, which is determined by the dependence:

$$
\lambda=\frac{v_{1}}{v_{2}}
$$

where: $v_{1}$ - speed of the biomass movement in the phase of its transportation to the threshing harvester;

$v_{2}$ - speed of the harvester's movement.

An increase in the ratio $\lambda$ leads to a break in the flow of pea biomass and to harmful mechanical effects on the beans, which crack, and the seeds fall to the ground. With a decrease in the ratio $\lambda$, the biomass of peas is unloaded in front of the picker and it also leads to seed losses.

To avoid unnecessary effects of the working bodies of the platform-pickup attachment on beans, the speed of the pea biomass layer in the transportation phase to the threshing machine should be close to the speed of the machine, i.e., the harvesting unit or slightly above the speed. We found that the ratio $\lambda$ depends on the yield and moisture content of the biomass of peas, as well as on crop infestation. In our experiments, the value $\lambda$ is in the range of $0.8 \ldots 0.15$.

The speed of the harvester was in the range of $8 \ldots 10 \mathrm{~km} / \mathrm{h}$. With the width of the platform-pickup attachment in 3,4 m and the threshing-separating harvester Don-1500 with optimal technological adjustments provided the high-quality threshing and cleaning of seeds from incoming mass.

Implementation experience in the agricultural enterprises of a new method and device for harvesting peas in extreme conditions (solid laying, and infestation showed its high efficiency. At the same time, the quantitative and qualitative losses of pea seeds were reduced by $5 . .10$ times (in comparison with agrotechnical requirements) and diesel fuel consumption by $30 \ldots 40 \%$.

We conducted controlled threshing of laid peas (after rains) and emergence of weeds in the fields of JSC "Plastunovskoye" of Dinskoy district of Krasnodar Territory and observations showed that the base unit (control), including the harvester "Don-1500" with frontal reaper (working width of $6 \mathrm{~m}$ ) harvested $1.44 \mathrm{t} / \mathrm{ha}$ of pea seeds in average. The fuel consumption was $9.3 \mathrm{~kg} / \mathrm{ha}$. The same harvester but with a platform-pickup attachment equipped with vertical disc knives (experience) on the same field threshed an average of $2.46 \mathrm{t} / \mathrm{ha}$ of pea seeds at fuel consumption of an average of $5.9 \mathrm{~kg} / \mathrm{ha}$.

Thus, the harvester Don-1500 with the platform-pickup attachment equipped with vertical disk knives provided increasing in collecting peas from unit of the area by 1,7 times in comparison with the harvester Don -1500 with a frontal reaper. At the same time, the economy of diesel fuel was $34 \%$.

Currently, we have developed a "method of peas gathering by direct harvesting and the 
unit for its implementation" which is widely used in a number of agricultural enterprises of Krasnodar Territory.

\section{References}

1. A. Aitemirov, T. Babaev, High protein forage for livestock sector, mountain agriculture, 4, p.47-51, (2015)

2. E. Mikhalev, V. Krivenkov, V. Ivanov, Pea cultivation, (2018)

3. A. Lozhkin, I.Eliseev, V.Dmitriev, Integrated system of pea protection, p. 245-248, (2018)

4. V.Ermak, V. Kolesnikov, A. Kolesnikov, Substantiation of optimal parameters of threshing-separating differential threshing of leguminous plants, 1-1(19), p.51-60, (2016)

5. A. Vasin, Influence of productivity of leguminous plants at introduction of fertilizers on planning crop capacity, Forage production, 7, p. 18-23, (2014)

6. V. Karpenko, New way of laid peas harvesting, Engineering in agriculture, 2, (1999)

7. V. Karpenko, Way of pea gathering by direct harvesting and a unit for its implementation, Patent 2096942 RF 33, (1987) 